\title{
Multiaxial fatigue study on steel transversal attachments under constant amplitude proportional and non-proportional loadings
}

\author{
Martin Garcia ${ }^{1, *}$, Claudio A. Pereira Baptista ${ }^{2}$, and Alain Nussbaumer ${ }^{1}$ \\ ${ }^{1}$ EPFL - Swiss Federal Institute of Technology, Resilient Steel Structure Laboratory (RESSLab), 1015 Lausanne, Switzerland \\ ${ }^{2}$ GRID International - Consulting Engineers, av. João Crisóstomo, 1050-125 Lisboa, Portugal
}

\begin{abstract}
In this study, the multiaxial fatigue strength of full-scale transversal attachment is assessed and compared to original experimental results and others found in the literature. Mild strength S235JR steel is used and an exploratory investigation on the use of high strength S690QL steel and the effect of nonproportional loading is presented. The study focuses on non-load carrying fillet welds as commonly used in bridge design and more generally between main girders and struts. The experimental program includes 33 uniaxial and multiaxial fatigue tests and was partially carried out on a new multiaxial setup that allows proportional and non-proportional tests in a typical welded detail. The fatigue life is then compared with estimations obtained from local approaches with the help of 3D finite element models. The multiaxial fatigue life assessment with some of the well-known local approaches is shown to be suited to the analysis under multiaxial stress states. The accuracy of each models and approaches is compared to the experimental values considering all the previously cited parameters.
\end{abstract}

\section{Introduction}

In bridge design, welded joints submitted to multiaxial stresses interaction are generally fillet welds that can be classified in two types, i.e. load carrying and non-load carrying fillet welds as shown in Fig. 1.

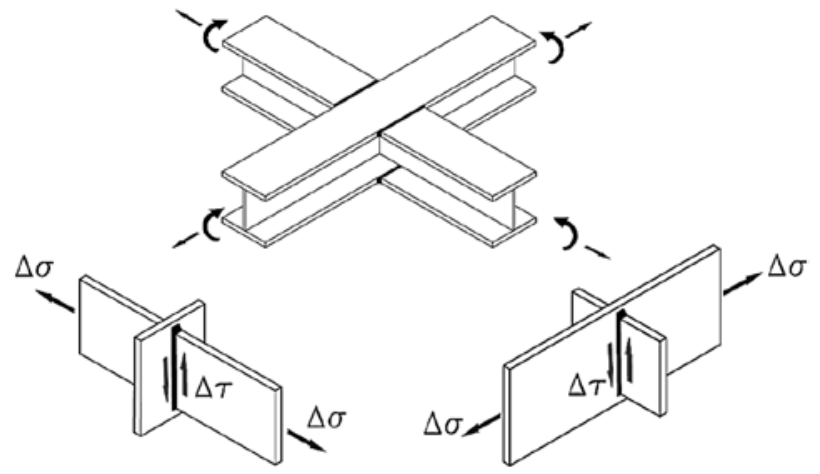

(a)

(b)

Fig. 1. Multiaxial normal-shear stress interaction in a typical bridge detail according to Baptista [1]

Detail (a) is relatively well reported in literature. It is a cruciform joint $(\mathrm{CJ})$ characterized by the fact that the main tensile or bending efforts are carried by the weld, leading to a higher variability in the critical location under multiaxial stresses, i.e. the weld throat or toe, depending mainly on the size and penetration of the fillet weld. For standard fillet weld, failure usually initiates at the weld root with cracks developing into the throat section $[2,3]$. On the contrary, detail (b) represents the so-called transversal attachment (TA), generally seen between for example main girders and secondary elements. It consists in a continuous plate subjected to a main tensile or bending stress, with transversal shear carrying fillet welds on its surface. Indeed, transversal attachments are usually loaded in shear, meaning that the weld toe on the main plate will experience an additional shear stress interacting with the main normal stress. No fatigue tests on this type of detail under multiaxial proportional or nonproportional loads were found in the literature, for any steel grade. Both details are considered in this study.

\section{Experimental campaign}

The experimental program was mainly carried out on a new multiaxial setup that allows for proportional and nonproportional tests. It includes 33 fatigue tests under uniaxial and multiaxial stress on details CJ (a) and TA (b) according to the matrix of experiments in Table 1 . The two details are considered, depending on whether the tests are carried out under uniaxial normal stresses or multiaxial stresses. Effects related to the use of high strength steel are explored on the multiaxial TA detail. Six specimens were tested under uniaxial normal stress on detail CJ and combined to data acquired in a literature review previously done by one of the authors (Baptista [1] in the Appendix A4) to allow for the FAT classification of the detail. The classification in shear, due to some limitation of the setup (see 1.2.2), is only based on a literature data review (Baptista [1] in the Appendix A6). A total of 27 tests were done on detail (b) with 17 specimens tested proportionally and 10 nonproportionally with a $180^{\circ}$ out-of-phase shift (the influence of the phase shift will be studied in a subsequent task). Specimens failed at the weld toe, both under

\footnotetext{
* Corresponding author: martin.garcia@epfl.ch
} 
Table 1. Matrix of experiments

\begin{tabular}{|c|c|c|c|c|c|c|c|c|c|c|}
\hline $\begin{array}{c}\text { Steel } \\
\text { grade }\end{array}$ & $\begin{array}{c}\Delta \mathbf{F}_{\text {hor }} \\
{[\mathrm{kN}]}\end{array}$ & $\begin{array}{c}\Delta \mathbf{F}_{\text {vert }} \\
{[\mathrm{kN}]}\end{array}$ & $\begin{array}{c}\Delta \sigma \\
{[\mathrm{MPa}]}\end{array}$ & $\begin{array}{c}\Delta \tau \\
{[\mathrm{MPa}]}\end{array}$ & $\mathbf{R}_{\sigma}$ & $\lambda_{\tau / \sigma}$ & $\begin{array}{c}\text { Phase } \\
{\left[{ }^{\circ}\right]}\end{array}$ & $\begin{array}{l}\# \text { of } \\
\text { tests }\end{array}$ & Detail & \\
\hline \multirow{4}{*}{ S235JR } & 180 & - & 180 & - & 0.1 & - & - & 1 & & $\mathrm{CP}$ \\
\hline & 150 & - & 150 & - & 0.1 & & & 3 & & \\
\hline & 120 & - & 120 & - & 0.1 & - & - & 1 & & \\
\hline & 100 & - & 100 & - & 0.1 & - & - & 1 & & 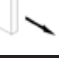 \\
\hline \multirow{3}{*}{ S235JR } & 0 & 100 & 54 & 50 & 0.1 & 0.93 & 0 & 3 & 1 & TA \\
\hline & 100 & 100 & 154 & 50 & 0.1 & 0.32 & 0 & 8 & & \\
\hline & 100 & 100 & 46 & 50 & 0.6 & 1.10 & 180 & 10 & 9 & \\
\hline \multirow{2}{*}{ S690QL } & 100 & 100 & 154 & 50 & 0.1 & 0.32 & 0 & 4 & & \\
\hline & 38 & 117 & 104 & 60 & 0.1 & 0.58 & 0 & 2 & & 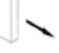 \\
\hline
\end{tabular}

uniaxial, multiaxial, proportional and non-proportional stress state.

In order to be consistent with usual bridge state of stress in specific details and because of setup limitations, a unique stress ratio $R=S_{\min } / S_{\max }$ of 0.1 is used except in the case of multiaxial non-proportional loading, where an initially unaccounted additional tensile stress (see 2.1) increased the $R$ ratio to 0.6 . In order to emphasize the detrimental influence of the shear stress on the normal uniaxial fatigue life, the shear to normal stress ratio $\lambda$ is comprised between 0.32 , which correspond to a more realistic bridge loading situation, and 1.1 .

\subsection{Experimental setup}

All the S235JR mild steel specimens were produced by C. Baptista, who is a former welder, at the EPFL-ICOM laboratory with commercial flat bars, whereas all S690QL high strength quenched and tempered steel specimens where fabricated by a steel fabricator. The specimen geometry consists of two orthogonally welded plates loaded in their planes as shown in Fig. 2.
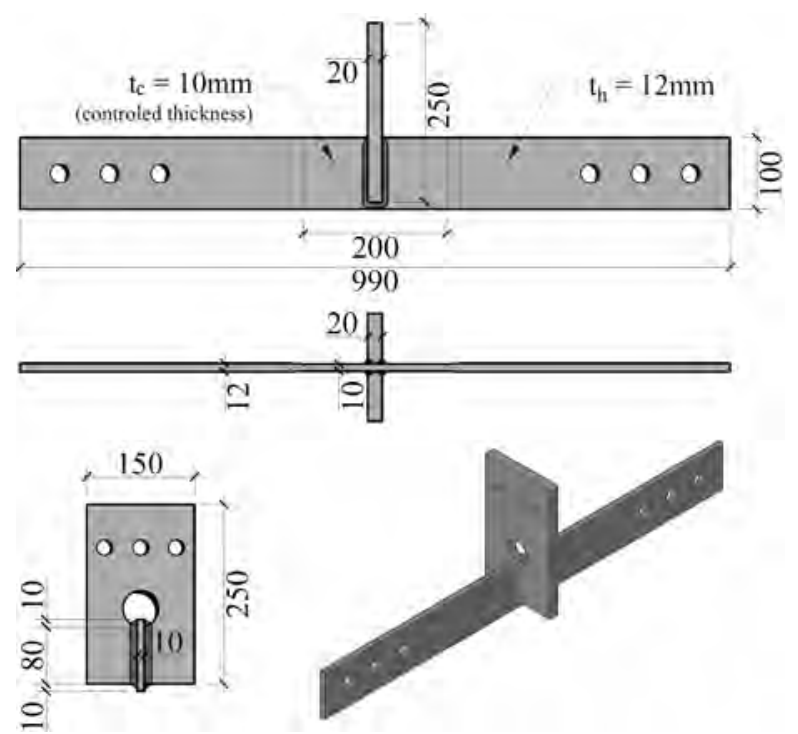

Fig. 2. Transversal attachment (TA) specimen geometry
The longitudinal plate is continuous and has a section of $100 * 12 \mathrm{~mm}$ while the second plate is a rigid and not continuous plate with a section of $150 * 20 \mathrm{~mm}$. To ensure crack to initiate at the weld toe on the main longitudinal plate and nor at the weld root neither on the longitudinal material, full penetration welds and a smooth reduction of the thickness to $10 \mathrm{~mm}$ over $200 \mathrm{~mm}$ of the plate at the location of interest are applied. To avoid weld defects at the longitudinal plate lower edge, vertical welds length is $80 \mathrm{~mm}$, leaving a $10 \mathrm{~mm}$ distance to the plate edges (see Fig. 2 and Fig. 7). The welding was made using either a MAG 136 (for S235) or a MAG 138 (for S690) with welldefined parameters available upon request to the authors.

The TA setup is based on two orthogonal jacks allowing the application of forces in two directions. The TA specimen is fixed horizontally to a column on one side and to the horizontal jack on the other side. Due to this support condition, a small horizontal displacement is occurring at the middle point and a larger one on the loaded side. To ensure the application of the defined normal stress range at the weld toe and to avoid any interaction between the two orthogonal jacks, the TA specimen is simply supported vertically on its bottom side by two linear roller bearing sliders while the vertical load is applied by the vertical jack above the specimen. Due to the support conditions and plate slenderness, only tensile loads can be applied horizontally to avoid any effects of elastic buckling or slipping at bolted connections. Vertically, in order to maintain contact with the roller bearing sliders, only compressive loads can be applied.

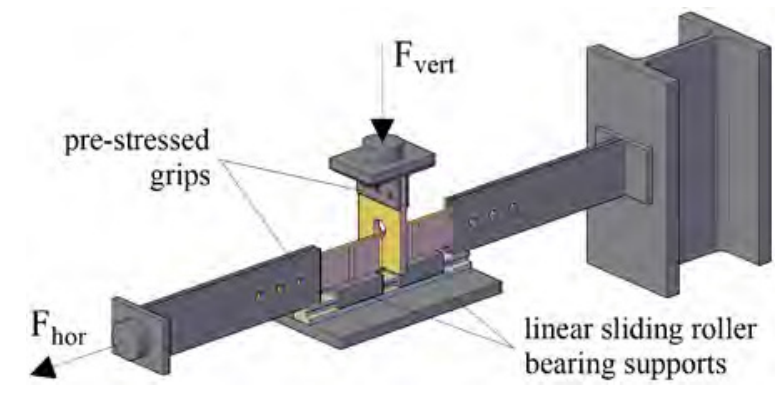

Fig. 3. TA setup operation scheme 


\subsection{Experiments under uniaxial stresses}

\subsubsection{Experiments under normal stresses}

Six specimens were tested under uniaxial normal stresses. A summary of the results is shown in Table 2. Different stress levels were applied during the tests to allow the definition of the S-N slope and therefore the FAT classification of the detail. The observed cracks are typical of mode I. Their pattern is similar among all the tested specimens, showing multiple semi-elliptical cracks that have initiated at the weld toe, with no preferential initiation point, and that have coalesced and propagated in the longitudinal plate perpendicularly. To ensure this behaviour and that initiation do not start specifically at the weld toe on any of the four longitudinal plate edges, these specific areas were smoothly grinded to avoid any notch or unwanted stress concentration effect. These results under uniaxial normal stress, together with the existing database, were already presented [1] and are shown in Fig. 4 along with their mean S-N curve. As the total number of tests is limited, a fixed slope $\mathrm{m}=3$, is considered, leading to a detail mean strength of $\Delta \sigma_{2 \cdot 10^{6}}=120 \mathrm{MPa}$. The database contains results for specimens with toe-to-toe length smaller than $l=80 \mathrm{~mm}$ that failed at the weld toe on the main plate and with $R \geq 0$. Procedure for the statistical analysis follows the IIW recommendations [4] as well as Schneider and Maddox [5], see [1] Appendix A for details. Finally, whether or not data from the literature are considered, the detail is classified as FAT80 with a confidence level $p=95 \%$. Results are in good agreement with values given in the IIW [4] and EC3 [6]

\subsubsection{Data under shear stresses}

One limitation of the setup in its actual design is that it is impossible to create a pure nominal shear stress because of the space between the two roller bearing supports inherent to their geometry (see Fig. 7). Roller bearings are installed as close as possible from the centre axis of the vertical plate, and therefore of the vertical jack, but a bending effect is still present due to the $75 \mathrm{~mm}$ distance imposed by the bearings design, which induces an additional normal stress due to the vertical load as shown in Fig. 7. However, a minimum span of the toe-to-toe distance is necessary in order to avoid a direct load transfer from the vertical plate to the roller bearing without having full transfer of the shear stress passing thru the weld toe.

As for the uniaxial test data, existing shear fatigue results were collected from the literature and presented previously in [1] (Appendix A.6). Relevant shear fatigue tests found in the literature were mainly done on tube-toplate specimens and a few on welded plates. An applied stress ratio of generally $R=-1$ was applied and only a few tests were done with $R \geq 0$. The re-analysis is given in Fig. 5 and shows that the mean strength is defined by $\Delta \tau_{2 \cdot 10^{6}}=132 \mathrm{MPa}$ with a fixed slope $\mathrm{m}=5$, the derived category being FAT98.
Table 2. Experimental results for CJ under uniaxial normal stresses (steel S235JR)

\begin{tabular}{ccccc}
\hline Specimen & $\begin{array}{c}\Delta \mathbf{F}_{\text {hor }} \\
{[\mathbf{k N}]}\end{array}$ & $\begin{array}{c}\Delta \boldsymbol{\sigma}_{\text {hor }} \\
{[\mathbf{M P a}]}\end{array}$ & $\mathbf{R}_{\boldsymbol{\sigma}}$ & $\mathbf{N}_{\text {failure }}$ \\
\hline N1 & 180 & 180 & 0.1 & $261^{\prime} 740$ \\
N2 & 150 & 150 & 0.1 & $657^{\prime} 360$ \\
N4 & 150 & 150 & 0.1 & $1^{\prime} 390^{\prime} 890$ \\
N5 & 150 & 150 & 0.1 & $626^{\prime} 460$ \\
N3 & 120 & 120 & 0.1 & $2^{\prime} 721^{\prime} 530$ \\
N6 & 100 & 100 & 0.1 & $9^{\prime} 000^{\prime} 000^{*}$ \\
\hline * run-out & & & &
\end{tabular}

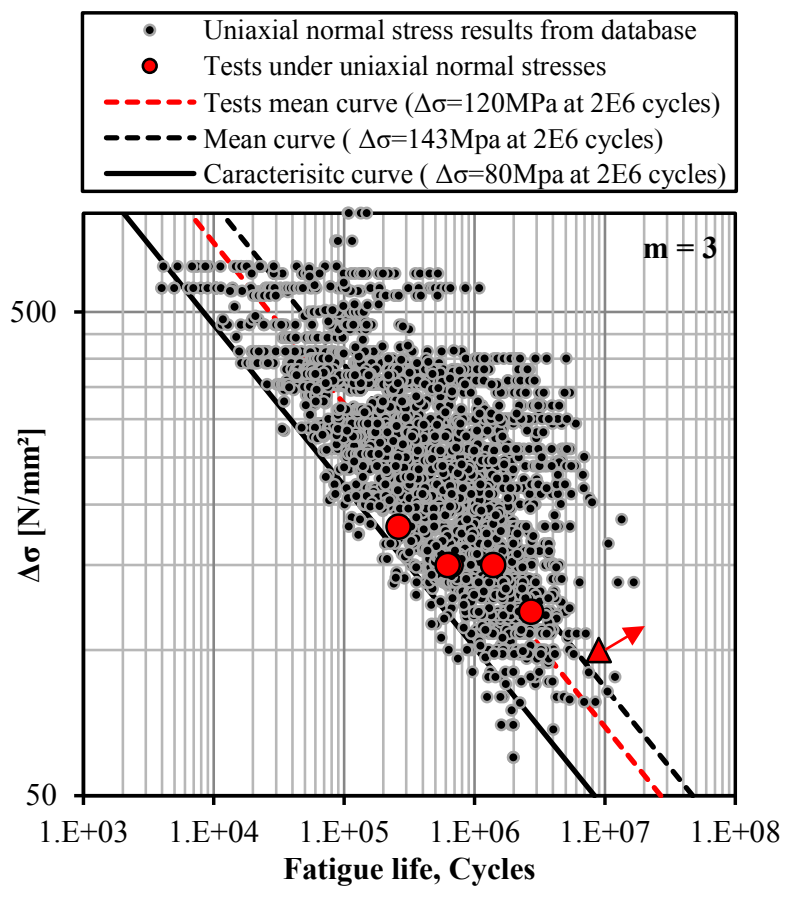

Fig. 4. Uniaxial CJ test results under normal stresses and comparison with results from database

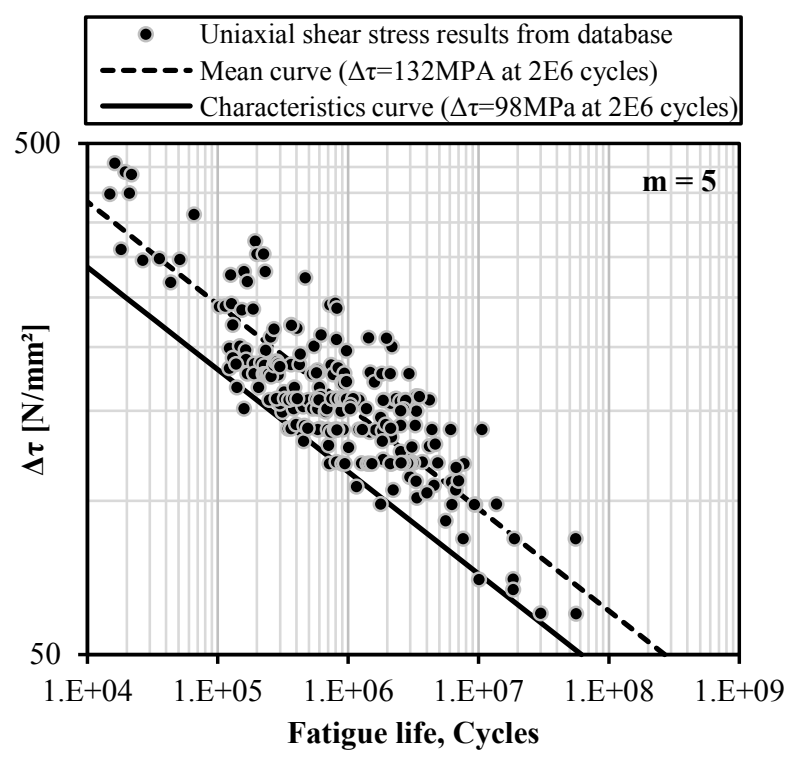

Fig. 5. Uniaxial shear stress database results and analysis (mainly on tube-to-plate specimens) 


\subsection{Experiments under multiaxial stresses}

A total of 27 specimens were tested under various multiaxial states of stress. Twenty-one tests were done on S235JR steel, including 11 tests under proportional and 10 tests under non-proportional loadings. Six tests were done on S690QL steel specimens under proportional loadings. In order to assess the detrimental or beneficial effects of these various situations, results are first shown in the usual nominal normal stress range to number of cycles domain and compared to the uniaxial normal stress results. As a first approach, nominal stresses are defined in a two-dimensional plane at the expected and observed location of crack initiation, i.e. at the bottom of the weld toe, as shown in Fig. 7. Applied load signals and nominal stresses output are presented in Fig. 9. Tests were carried at frequencies between 3 and $4 \mathrm{~Hz}$ depending on the loading situation.

Table 3. Experimental results on TA under multiaxial proportional $(\mathrm{P})$ and non-proportional (NP) stresses $(\sigma$ and $\tau$ )

\begin{tabular}{|c|c|c|c|c|c|c|}
\hline & Test & $\begin{array}{c}\Delta \sigma_{h o r} \\
{[\mathrm{MPa}]}\end{array}$ & $\begin{array}{c}\Delta \tau_{\text {vert }} \\
{[\mathbf{M P a}]}\end{array}$ & $\mathbf{R}_{\sigma}$ & $\lambda_{\tau / \sigma}$ & $\mathbf{N}_{\text {failure }}$ \\
\hline \multirow{21}{*}{$\begin{array}{l}\tilde{\sigma} \\
\tilde{n} \\
\tilde{N} \\
\tilde{\omega}\end{array}$} & $\mathrm{P} 1$ & 54 & 50 & 0.1 & 0.93 & 3'780'000 \\
\hline & $\mathrm{P} 2$ & 54 & 50 & 0.1 & 0.93 & $10^{\prime} 000^{\prime} 000^{*}$ \\
\hline & P3 & 54 & 50 & 0.1 & 0.93 & $10^{\prime} 000^{\prime} 000^{*}$ \\
\hline & P4 & 154 & 50 & 0.1 & 0.32 & $174^{\prime} 000$ \\
\hline & P5 & 154 & 50 & 0.1 & 0.32 & $240^{\prime} 500$ \\
\hline & P6 & 154 & 50 & 0.1 & 0.32 & $192^{\prime} 500$ \\
\hline & P7 & 154 & 50 & 0.1 & 0.32 & $306^{\prime} 000$ \\
\hline & P8 & 154 & 50 & 0.1 & 0.32 & $330^{\prime} 000$ \\
\hline & P9 & 154 & 50 & 0.1 & 0.32 & $253^{\prime} 000$ \\
\hline & $\mathrm{P} 10$ & 154 & 50 & 0.1 & 0.32 & $291^{\prime} 000$ \\
\hline & $\mathrm{P} 11$ & 154 & 50 & 0.1 & 0.32 & $486^{\prime} 900$ \\
\hline & NP1 & 46 & 50 & 0.6 & 1.10 & 1'550'000 \\
\hline & NP2 & 46 & 50 & 0.6 & 1.10 & $4^{\prime} 052^{\prime} 500$ \\
\hline & NP3 & 46 & 50 & 0.6 & 1.10 & $3^{\prime} 200^{\prime} 000$ \\
\hline & NP4 & 46 & 50 & 0.6 & 1.10 & $2^{\prime} 000^{\prime} 000$ \\
\hline & NP5 & 46 & 50 & 0.6 & 1.10 & $5^{\prime} 000^{\prime} 000$ \\
\hline & NP6 & 46 & 50 & 0.6 & 1.10 & $5^{\prime} 500^{\prime} 000$ \\
\hline & NP7 & 46 & 50 & 0.6 & 1.10 & $1^{\prime} 560$ '000 \\
\hline & NP8 & 46 & 50 & 0.6 & 1.10 & $3^{\prime} 282^{\prime} 500$ \\
\hline & NP9 & 46 & 50 & 0.6 & 1.10 & $10^{\prime} 000^{\prime} 000^{*}$ \\
\hline & NP10 & 46 & 50 & 0.6 & 1.10 & $10^{\prime} 000^{\prime} 000^{*}$ \\
\hline \multirow{6}{*}{$\begin{array}{l}\partial \\
8 \\
0 \\
0 \\
0\end{array}$} & P12 & 154 & 50 & 0.1 & 0.32 & $532 ' 500$ \\
\hline & $\mathrm{P} 13$ & 154 & 50 & 0.1 & 0.32 & $503 ' 600$ \\
\hline & $\mathrm{P} 14$ & 154 & 50 & 0.1 & 0.32 & $410^{\prime} 000$ \\
\hline & $\mathrm{P} 15$ & 154 & 50 & 0.1 & 0.32 & $236^{\prime} 000$ \\
\hline & P16 & 143 & 60 & 0.1 & 0.58 & $151^{\prime} 500^{\circ}$ \\
\hline & P17 & 143 & 60 & 0.1 & 0.58 & $208^{\prime} 000^{\circ}$ \\
\hline
\end{tabular}

Among all specimens, cracks initiated and propagated in the lower part of the weld toe section into the longitudinal plate, i.e. the same section and crack plane as under uniaxial normal stresses. Multiple semi-elliptical cracks initiated in this area and coalesced into a single one with a high $a / c$ ratio. The bigger the shear ratio, the more the crack pattern tends to a semi-circular shape due mainly to the Mode II. Exceptions to mention are the specimens P16 and P17 where the crack initiated from a small notch on the lower edge of the main plate at the symmetry axis of the vertical plate. This area being subjected to the maximum principal stress when under multiaxial loads, any welding notch or imperfection needs to be carefully eliminated. Unlike the uniaxial case, crack surfaces are rough and presents small branches that are typical of Mode II/III cracks see Fig. 6. The bigger the ratio between shear and normal stress, the more the observable Mode II and III. These tests also show the anisotropic nature of the multiaxial fatigue propagation phenomenon in welded plate details. Most of the crack propagation driving force is lost in friction so these modes have higher lives than their corresponding Mode I cracks. The shear friction may however be severely reduced under the presence of a normal stress. The idea of factorising the shear damage with the normal stress influence can be found in most of the important strainbased criteria, e.g. Findley [7], which however are initiation criteria. In propagation and at macroscopic level, we believe this phenomenon to be the main reason for the lowest fatigue lives of the proportional load case. The normal stress influence, acting in phase with the shear, greatly reduces friction between the crack surfaces, increasing the damaging character of the shear forces.

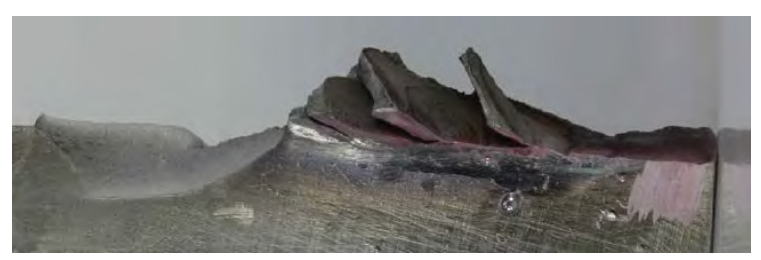

Fig. 6. Typical crack pattern under multiaxial stresses with a high ratio $\tau / \sigma=0.93$ (specimen $\mathrm{P} 1)$

In bridge and other structures design, fatigue under shear and its relative failure modes are generally neglected in plate details because of the relative lack of tests on these types of details. It is effectively easier to obtain mode II and III in tubular specimens from pure torsion tests. In this regard, the new multiaxial setup presented in this paper showed to be well suited.

The first conclusion that can be drawn is that multiaxial loadings are definitely more damaging than uniaxial loading situations when looking only at the uniaxial stresses. Results in Fig. 8 shows the detrimental effect on the fatigue life of an additional cyclic shear stress acting in combination to the cyclic normal stress. As for uniaxial tests, linear regressions are done with a fixed slope of 3 due to the limited number of specimens tested at only a few different levels of stresses. The linear regression of the proportional results gives a mean strength of $\Delta \sigma_{2 \cdot 10^{6} \text {,mean }}=82 \mathrm{MPa}$. The nonproportional load case significantly reduces uniaxial fatigue life with regard to the obtained results expressed in terms of nominal stresses. The corresponding mean fatigue strength is $\Delta \sigma_{2 \cdot 10^{6} \text {,mean }}=57 \mathrm{MPa}$. This conclusion is in accordance to what has been observed in multiaxial tests on tubular specimens where the nonproportional load case has been reported as more damaging in ductile material because of grain dislocations 


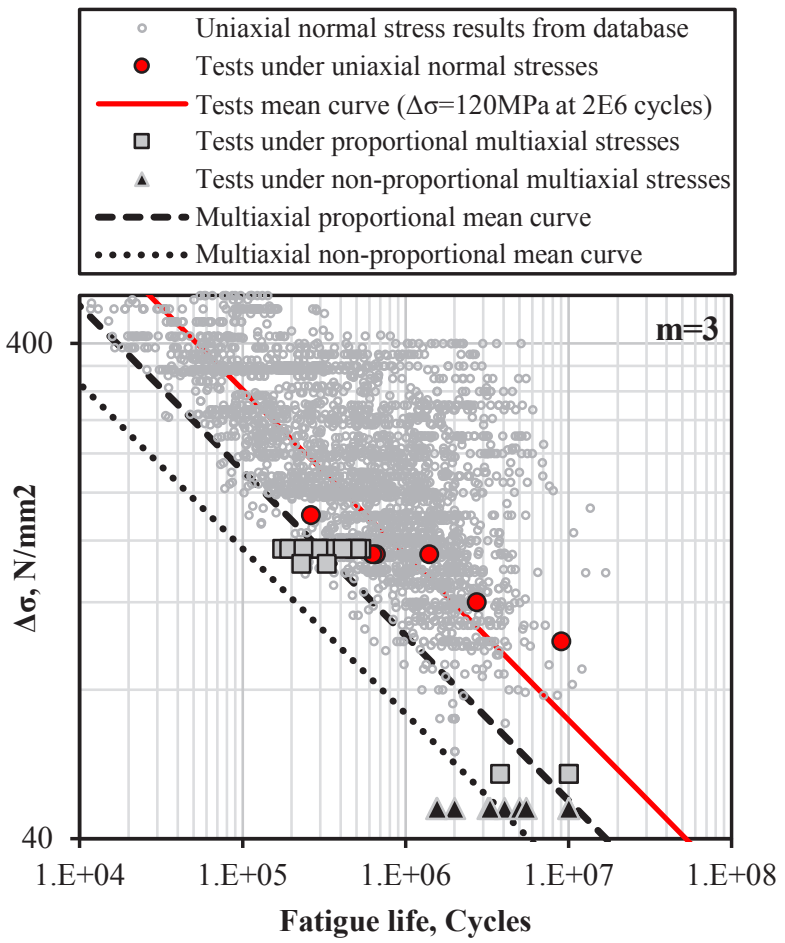

Fig. 2. Multiaxial fatigue tests plotted on the uniaxial normal stress to fatigue life space

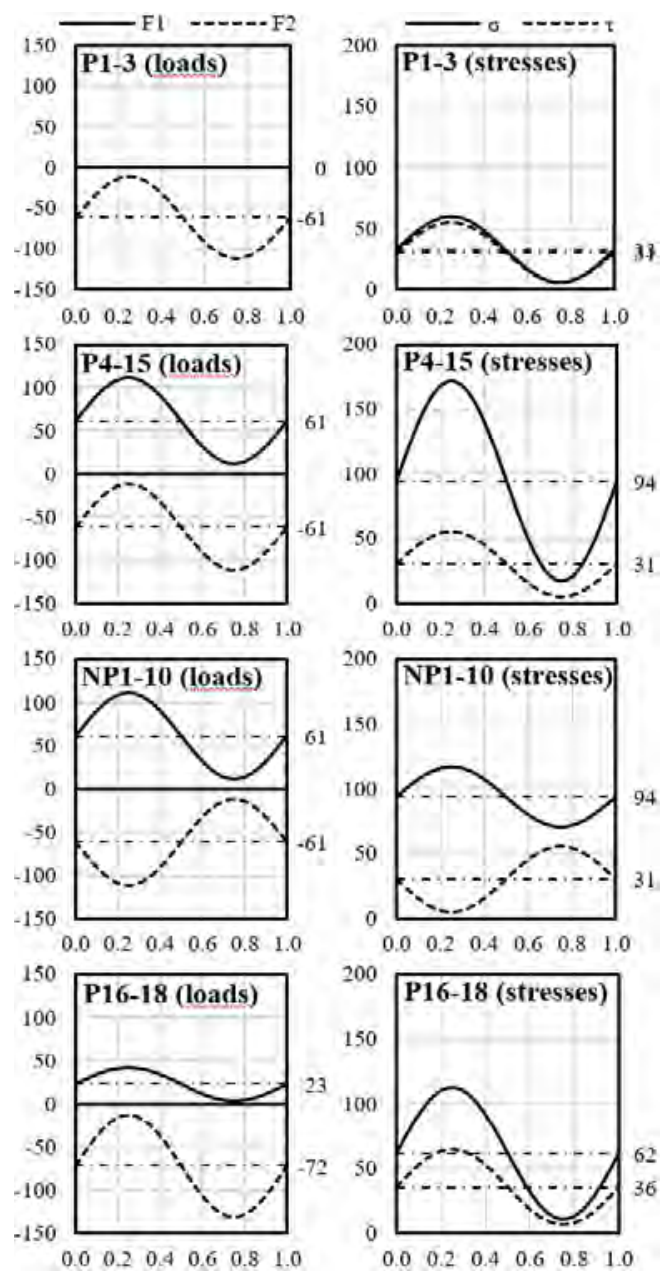

Fig. 3. Loads and nominal stresses signal during one cycle for the four different multiaxial combinations tested
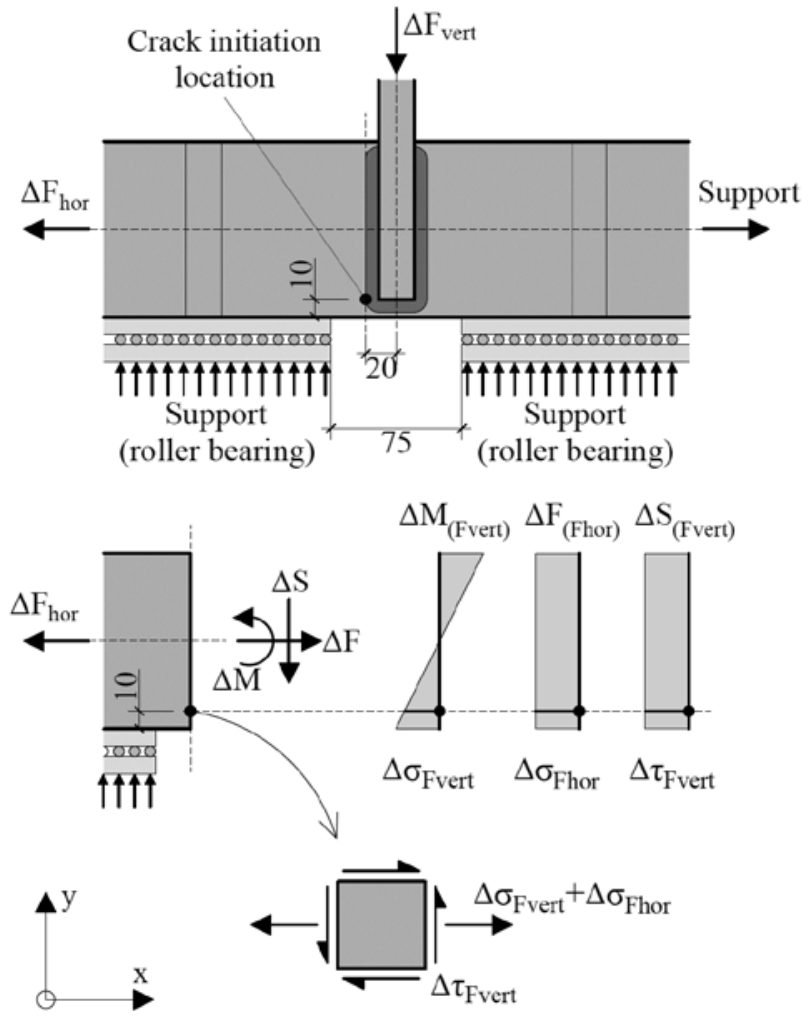

Fig. 1. Detail of the vertical support system and weld geometry. Definition of the crack initiation location and simplified determination of the nominal stresses.

that occur when the principal stress plane angle varies during the loading cycle. The difference may also come from the use of a very high $\lambda$ ratio of 1.10 , but on the other hand, a very low stress amplitude puts the tests very close to the theoretical fatigue limit and thus the fatigue life should increase. This is effectively seen with both specimens NP9 and NP10 whom have reached the fatigue life of $10^{7}$ cycles before being stopped and considered as run-outs. An important remark is that these tests were carried out with a shift angle of $180^{\circ}$. A $90^{\circ}$ phase shift should be more damaging but this influence will only be studied in a subsequent task.

It is not possible to draw a general conclusion on the use of high strength steel due to the very low number of specimens tested to date. However, if specimens P16 and $\mathrm{P} 17$ are neglected due to their different initiation location, the mean fatigue strength is equal to $\Delta \sigma_{2 \cdot 10^{6} \text {,mean }}=$ $80 \mathrm{MPa}$ for $\mathrm{S} 235 \mathrm{JR}$ specimens and $\Delta \sigma_{2 \cdot 10^{6} \text {,mean }}=$ $90 \mathrm{MPa}$ for $\mathrm{S} 690 \mathrm{QL}$ specimens indicating a possible improvement in the fatigue strength for the high strength steel.

\section{Multiaxial fatigue approaches for fatigue life estimation}

Models and criteria presented in this paper can be separated in three groups, i.e. equivalent stresses, equivalent stresses on the critical plane and interaction equations approaches. Most of them were initially used or defined to assess the fatigue life up to crack initiation, to the so-called technical crack size i.e. from 0.01 to $1 \mathrm{~mm}$ in 
general. To study the total fatigue life, these models should be combined with propagation approaches based on fracture mechanics. Several authors $[8,9]$ concluded that even for welded joints an average factor of 0.5 is observed between the time to initiate a $1 \mathrm{~mm}$ deep crack and through-thickness cracking, for both as-welded and weld machined and ground [13].

\subsection{Modelling and stress definition with the effective notch stress approach}

The effective notch stress is part of the various notch stress approaches as explained by Radaj et al. [10]. The fatigue notch factor defining the effective stress concentration is determined with the help of a microstructural notch support hypothesis. The maximum notch stress is determined by an averaging over a material-characteristic small-length, area or volume at the notch, see for example Peterson [11], Neuber [12-14], Taylor [15]. Olivier et al. [16, 17] confirmed the validity of the notch stress approach according to Radaj, for several weld configurations, including the scatter due to different notch values and the effect of stress ratio. They also concluded that even if a higher strength steel offers a better local fatigue strength on smooth specimens, it is also more sensitive to notch sharpness. Thus, in its application, even if the approach was proposed for any notch radius, one generally use the theoretical worst case, leading to the popular fictitious notch radius $\rho_{f}=1 \mathrm{~mm}$.

This approach is used to model any notch at the expected crack location, weld toe or root, with a fictitious transition radius of $1 \mathrm{~mm}$. The numerical FE model is developed in Abaqus 6.16 (Dassault Systèmes) and a submodelling approach is used to model the transition radius. Hexahedral quadratic elements with reduced integration (C3D20R) are used in both global and sub-models. The IIW [4] recommends to discretize the radius by minimum 4 quadratic elements or 6 linear elements. Six elements are used in the model.

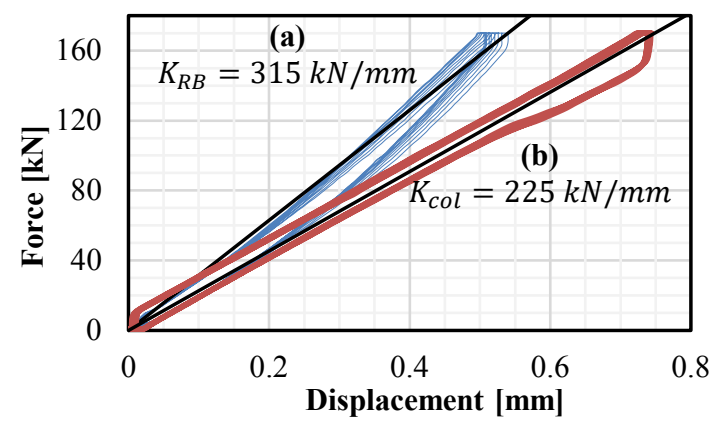

Fig. 10. (a) linear roller bearings vertical stiffness and (b) column horizontal stiffness measured with LVDTs

One important feature of the setup is that it is not purely symmetrical, implying that the FE model cannot be simplified and flexible supports have to be taken into account. The linear roller bearings and the column are modelled with spring elements supporting the edges of the main horizontal plate. Calibration of the spring elements in the FE model is made with the help of measured displacements on the specimens during several quasi- static uniaxial and multiaxial loading situations. As shown in Fig. 10, the behaviour of the spring elements proved to be relatively linear.

The allowable value for structural steels used in bridge and ship welded construction according to the IIW is FAT225/3 (i.e. $225 \mathrm{MPa}$ at 2 million cycles and slope $\mathrm{m}$ $=3$, with $97,7 \%$ survival probability, $\mathrm{R} \leq 0.5$ ). Furthermore, the FAT160/5 proposed by Sonsino [18] for the assessment of welded joints loaded in pure torsion/shear is chosen as the shear fatigue strength.

\subsection{Equivalent stress approaches}

If, in general, most of the multiaxial fatigue situations can be simplified into a two-dimensional system, the studied geometry and its relative stress state intricacy at the location of interest implies to consider a threedimensional stress tensor when using local approaches. The principal stresses (PS) is used first in the analysis.

Secondly, the von Mises criterion is used. Indeed, Radaj et al. [10] stated that one should use the Von Mises equivalent stress combined with the effective notch stress in case of ductile material instead of the maximum principal normal stress that is more suited to brittle material as cast steel.

\subsection{Findley critical plane approach}

Critical plane approaches are all based on the research of the one or multiple planes that maximizes a specific damage parameter. The critical plane search method (CPS) used in this paper is similar to the minimum circumscribed circle concept proposed by Dang Van [19] and Papadopoulos [20, 21]. This new CPS method proposed by Karpanan [22] can be used for all stress based proportional and non-proportional loading fatigue analysis and all strain-based fatigue analysis methods. The stress tensor in each material point is needed but in this paper two points (nodes) on the FE models are analysed for sake of simplification, i.e. the points subjected to the maximum principal stress and to the maximum von Mises equivalent stress. Pedersen [23] has recently shown that, when using the effective notch stress approach, for CA proportional loadings, Findley's [7] simple critical plane criterion leads to the safest predictions. The Findley criterion suggest that the maximum normal stress $\sigma_{n}$, acting in combination with the shear amplitude $\Delta \tau / 2$ on a specific plane has a detrimental effect on the allowable alternating shear stress. The criterion is defined on the plane subjected to the maximum value of this combination,

$$
f=\left(\frac{\Delta \tau}{2}+k * \sigma_{n}\right)_{\max }
$$

where $k$ is a material constant related to materials' sensitivity to normal stresses and $f$ is directly related to the materials' shear fatigue strength. For ductile materials, $k$ usually varies between 0.2 and 0.3 . A value $k=0.3$ is used in the present paper. Findley's criterion $f$ is here directly compared to the shear fatigue strength FAT160/5. 


\subsection{EN1993-1-9 and IIW interaction equations}

In the IIW [4], the interaction criterion is a modified Gough-Pollard criterion eq.(2).

$$
\left(\frac{\Delta \sigma_{S}}{\Delta \sigma_{R}}\right)^{2}+\left(\frac{\Delta \tau_{S}}{\Delta \tau_{R}}\right)^{2} \leq C V
$$

The multiaxial comparison value $C V$ may have the value of 1,0 or 0,5 depending on the loading state (proportional or non-proportional) and the ductility of the material.

In the EC3 [6], the criterion is based on a linear damage sum $D$ according to Miner's rule eq.(3).

$$
\left(\frac{\Delta \sigma_{S}}{\Delta \sigma_{R}}\right)^{3}+\left(\frac{\Delta \tau_{S}}{\Delta \tau_{R}}\right)^{5} \leq D
$$

Unlike other models presented, the EC3 and IIW equivalent stresses are dependent of previously defined shear and normal fatigue strengths and comparison value or damage sum.

\section{Multiaxial fatigue criteria results}

The equivalent stress is calculated for each test and then plotted in SN diagrams for each criterion presented previously. However, in order to analyse the results and present them in a clear and brief manner, Table 4 gives the most important outcomes of the tests data expressed with the help of the five different criteria. A graphical example is given in Fig. 12, showing data plotted in terms of Findley's equivalent stresses defined with the effective notch stress approach. The notch stress has the ability to regroup the different load cases in a single scatter band but all criteria used in this paper lead to a large scatter when considering non-proportional tests except for the Findley critical plane approach, which showed good results. It is interesting to note that the characteristic curve for the uniaxial case with principal stresses is FAT227/3 which is in good agreement with the FAT225/3 from the IIW. In general, the IIW and EC3 criteria give the larger scatter. Table 4 also gives the probability of non-conservative prediction $p_{f}$ calculated with the help of a life ratio $l r$ as employed by Bruun \& Härkegard [24] and Pedersen [23],

$$
l r=\frac{\Delta S_{e q, N, i}}{\Delta S_{R, N}}
$$

where $\Delta S_{e q, N, i}$ is the equivalent strength at a specific number of cycles for each tests and $\Delta S_{R, N}$ is the design shear or normal fatigue strength at the same number of cycles. A Weibull distribution is then fitted to the life ratios for each situation. The resulting scale $\alpha$ and shape $\beta$ parameters are then used to compute the nonconservative prediction $p_{f}$, i.e. the probability that tests results have life ratios $l r<1.0$.

In the case of uniaxial and multiaxial proportional load cases, both the maximum principal stress and von Mises give results in the range of 12 to $20 \%$ but the principal stress gives overall better results. Again, the combination of Findley's equivalent stress with the effective notch stress method is the safest with a $p_{f}$ of $1.56 \%$. In the case of non-proportional loadings, all criteria overestimate the fatigue lives, giving a $p_{f}$ which tends to 0 this is mainly due to the very low strange range level resulting from the out-of-phase angle of $180^{\circ}$. In general, the IIW and EC3 gives surprisingly non-conservative values, with an advantage for the IIW that has better results even in the non-proportional case certainly due to the use of $C V=$ 0.5 in this case. It is important to mention that all these conclusions are mostly indicative because of the very

\begin{tabular}{|c|c|c|c|c|c|c|c|c|c|}
\hline & \multicolumn{3}{|c|}{ Uniaxial normal } & \multicolumn{3}{|c|}{$\begin{array}{c}\text { Uniaxial normal }+ \text { Multiaxial } \\
\text { proportional }\end{array}$} & \multicolumn{3}{|c|}{$\begin{array}{c}\text { Uniaxial normal + Multiaxial } \\
\text { proportional + non-proportional }\end{array}$} \\
\hline & $\begin{array}{l}\text { std. dev. } \\
\sigma\end{array}$ & $\begin{array}{l}\text { Mean } \\
{[\mathrm{Mpa}]}\end{array}$ & $\begin{array}{c}\text { FAT } \\
(\mathrm{p}=95 \%) \\
{[\mathrm{Mpa}]}\end{array}$ & $\begin{array}{l}\text { std. dev. } \\
\sigma\end{array}$ & $\begin{array}{l}\text { Mean } \\
{[\mathrm{Mpa}]}\end{array}$ & $\begin{array}{c}\text { FAT } \\
(\mathrm{p}=95 \%) \\
{[\mathrm{Mpa}]}\end{array}$ & $\begin{array}{l}\text { std. dev. } \\
\sigma\end{array}$ & $\begin{array}{l}\text { Mean } \\
{[\mathrm{Mpa}]}\end{array}$ & $\begin{array}{c}\text { FAT } \\
(\mathrm{p}=95 \%) \\
{[\mathrm{Mpa}]}\end{array}$ \\
\hline PS & 0.288 & 304 & 227 & 0.235 & 275 & 212 & 0.571 & 355 & 286 \\
\hline v. Mises & 0.288 & 272 & 203 & 0.231 & 261 & 202 & 0.538 & 331 & 180 \\
\hline Findley & 0.288 & 192 & 144 & 0.219 & 178 & 140 & 0.328 & 200 & 138 \\
\hline IIW & & & & 0.531 & 254 & 141 & 1.08 & 360 & 106 \\
\hline EC3 & & & & 0.461 & 232 & 139 & 0.823 & 302 & 119 \\
\hline
\end{tabular}
limited number of tests that are analyzed.

\begin{tabular}{|c|c|c|c|c|c|c|c|c|c|c|}
\hline & \multicolumn{2}{|c|}{ Uniaxial normal } & \multicolumn{2}{|c|}{ Multiaxial P } & \multicolumn{2}{|c|}{ Multiaxial NP } & \multicolumn{2}{|c|}{$\begin{array}{c}\text { Uniaxial + } \\
\text { Multiaxial P }\end{array}$} & \multicolumn{2}{|c|}{$\begin{array}{l}\text { Uniaxial normal + } \\
\text { Multiaxial } \mathbf{P}+\mathrm{NP}\end{array}$} \\
\hline & $l r_{\text {mean }}$ & $p f$ & $l r_{\text {mean }}$ & $p f$ & $l r_{\text {mean }}$ & $p f$ & $l r_{\text {mean }}$ & $p f$ & $l r_{\text {mean }}$ & $p f$ \\
\hline PS & 1.377 & $12.09 \%$ & 1.192 & $14.54 \%$ & 2.908 & $0.31 \%$ & 1.241 & $15.06 \%$ & 1.746 & $21.43 \%$ \\
\hline v. Mises & 1.234 & $21.10 \%$ & 1.156 & $20.50 \%$ & 2.604 & $0.53 \%$ & 1.177 & $20.23 \%$ & 1.609 & $23.04 \%$ \\
\hline Findley & 1.581 & $0.02 \%$ & 1.61 & $1.56 \%$ & 1.841 & $0.30 \%$ & 1.603 & $0.97 \%$ & 1.675 & $1.03 \%$ \\
\hline IIW & & & 1.078 & $28.15 \%$ & 3.656 & $0.10 \%$ & 1.148 & $25.06 \%$ & 1.908 & $27.00 \%$ \\
\hline $\mathrm{EC} 3$ & & & 0.996 & $48.16 \%$ & 2.542 & $0.60 \%$ & 1.055 & $39.13 \%$ & 1.506 & $29.18 \%$ \\
\hline
\end{tabular}

Table 2. Evaluation of the different multiaxial fatigue criteria. 


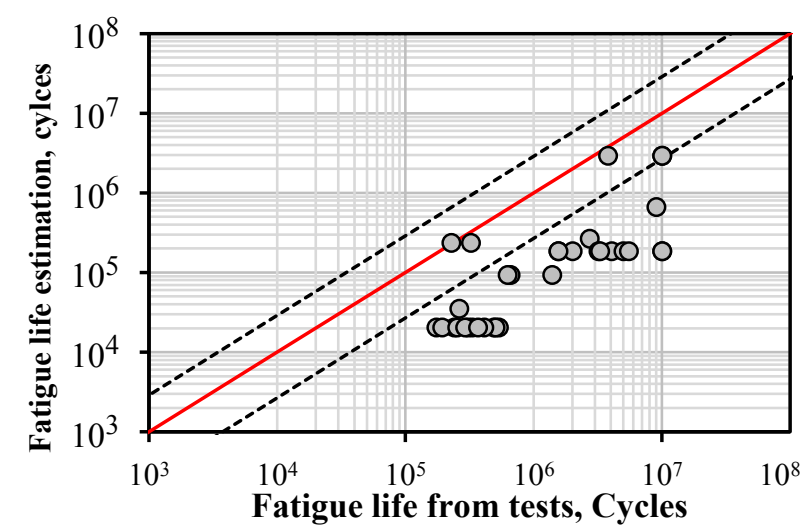

Fig. 11. Fatigue life estimation of all tests using the effective notch stress and Findley equivalent stress

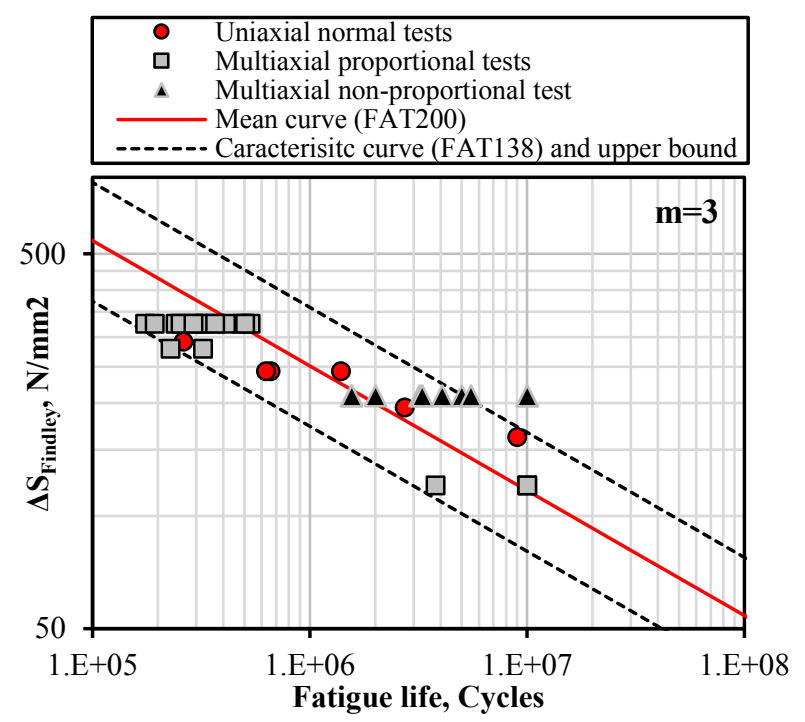

Fig. 12. Example of tests data represented using the effective notch stress and Findley equivalent stress

\section{Conclusions}

A new multiaxial setup was presented that allowed proportional and non-proportional multiaxial tests in a typical welded plate detail. Mode II/III cracks were obtained under multiaxial loadings tests. The results on a transversal attachments loaded both in normal stress $\Delta \sigma$ and shear stress $\Delta \tau$ clearly showed the detrimental effect of the multiaxial loadings. The local $1 \mathrm{~mm}$ effective notch stress approach was shown suitable to the analysis under multiaxial stress states. Combined to Findley's criterion and compared to the shear fatigue strength curve FAT160/5 or combined to the maximum principal stress range and compared to the normal fatigue strength curve FAT225/3, it proved to be both safe and the most accurate. Effects of the use of high strength steel was explored and even if results are scarce, one may expect an improvement in the total fatigue life under multiaxial loadings.

Among parameters to be considered in the future to improve the models:

- The influence of transverse residual stresses and their relaxation. Better knowledge would improve initiation life prediction with for example the Manson-Coffin relation using Neuber's notch rule and multiaxial strain based models e.g. Fatemie-Socie [25].

- Propagation life. Propagation measurements would allow calibration of a fracture mechanics model. This would be mostly valuable for the shear propagation under mixed Mode I, II and III. Indeed, mode II/III stress intensity factors are calibrated case by case after experiments as shown for example by Amstutz et al. [27].

- Phase shift angle.

\section{References}

1. C. Baptista, thesis, EPFL, Lausanne (2016).

2. I. Lotsberg, J. Offshore Mech. Arct. Eng. 131, 041302041302-9 (2009).

3. M. Bokesjö, M. Al-Emrani, T. Svensson, Int. J. Fatigue. 44, 21-31 (2012).

4. A. F. Hobbacher, Recommendations for Fatigue Design of Welded Joints and Components (Springer International Publishing, Cham, 2016)

5. C. R. A. Schneider, S. J. Maddox, 30 (2003).

6. Eurocode 3: Design of steel structures - Part 1-9: Fatigue (Comité européen de normalisation, Bruxelles, 2005)

7. W. N. Findley, A theory for the effect of mean stress on fatigue of metals under combined torsion and axial load or bending (1958)

8. T. Bruder, K. Störzel, J. Baumgartner, H. Hanselka, Int. J. Fatigue. 34, 86-102 (2012).

9. C. M. Sonsino, Int. J. Fatigue. 17, 55-70 (1995).

10. D. Radaj, C. M. Sonsino, W. Fricke, Fatigue assessment of welded joints by local approaches (2nd edition., 2006).

11. R. E. Peterson, Proc SESA. 11, 199-206 (1950).

12. H. Neuber, Theory of notch stresses: Principles for exact stress calculation (JW Edwards, 1946), vol. 74.

13. H. Neuber, Kerbspannungslehre: Theorie der Spannungskonzentration Genaue Berechnung der Festigkeit (Springer-Verlag, 2013).

14. H. Neuber, Konstruktion. 20, 245-251 (1968).

15. D. Taylor, The theory of critical distances: a new perspective in fracture mechanics (Elsevier, Amsterdam; Boston, 2007).

16. R. Olivier, V. B. Köttgen, T. Seeger, Forschungskuratorium Maschinenbau FKM Frankf. Forschungsheft. 143 (1989).

17. R. Olivier, V. B. Köttgen, T. Seeger, Forschungskuratorium Maschinenbau FKM FrankfurtMain Forschungsheft. 180 (1994).

18. C. M. Sonsino, T. Bruder, J. Baumgartner, Weld. World. 54, R375-R392 (2010).

19. K. Dang-Van, in Advances in multiaxial fatigue (ASTM International, 1993).

20. I. V. Papadopoulos, Fatigue Fract. Eng. Mater. Struct. 21, 269-285 (1998).

21. Papadopoulos IV, Fatigue Fract. Eng. Mater. Struct. 21, 269-285 (2002).

22. K. Karpanan, (ASME, 2016; http://proceedings.asmedigitalcollection.asme.org/proceed ing.aspx?doi=10.1115/PVP2016-63705)

23. M. M. Pedersen, Int. J. Fatigue. 83, 269-279 (2016).

24. A. Bruun, G. Härkegård, Int. J. Fatigue. 73, 1-16 (2015).

25. A. Fatemi, D. F. Socie, Fatigue Fract. Eng. Mater. Struct. 11, 149-165 (1988).

26. H. Amstutz, K. Störzel, T. Seeger, Fatigue Fract. Eng. Mater. Struct. 24, 357-368 (2001). 